\title{
Using Activity Theory for Modelling Transformative Digital Learning
}

\author{
Olena Mykhailenko \\ University of Ontario Institute of \\ Technology \\ Canada \\ olena.mykhailenko@collaboritsi.com \\ Todd Blayone \\ University of Ontario Institute of \\ Technology \\ Canada \\ todd.blayone@collaboritsi.com
}

\author{
Irēna Žogla \\ Rezekne Academy of Technologies \\ Latvia \\ irena.zogla@lu.lv
}

\author{
Velta Lubkina \\ Rezekne Academy of Technologies \\ Latvia \\ velta.lubkina@rta.lv
}

\begin{abstract}
In support of ongoing educational transformation in post-Soviet nations, this article positions activity theory (in the tradition of Engeström) as a framework for modelling changes towards innovative forms of collaborative, fully online digital learning. A strength of activity theory is that it adopts a holistic socio-technical perspective in which teachers, learners, technologies, pedagogical values, roles/identities and rules/cultures are considered together as interdependent elements of collective activity. An illustrative example is offered to model a current and envisioned (target) activity system. In addition, a few considerations to guide research are offered. These include an emphasis on measuring the general readiness of students and teachers, and the need to explore gender divides. The goal is to help envision program transformations towards online learning at two partner universities as part of Ukrainian and Latvian, government-funded projects.
\end{abstract}

Keywords-activity theory, educational reforms, online learning, transformative digital learning.

\section{INTRODUCTION}

Fundamental changes in society and technology have disrupted traditional socio-economic activities and triggered educational reinvention. Millions of jobs may be lost or reconfigured in the near future owing to advances in machine automation and human-machine symbiosis as envisioned, for example, by Industry 4.0 [1]. At the same time, many new (and currently unknown) professional roles will emerge requiring a more diverse workforce to develop advanced technological knowledge and skills, a positive disposition towards environmental and organizational change, strong competences for collaborating with both humans and intelligent machine agents, and creative problem-solving abilities [2]. The old concept of mass education, designed for the assembly line, focused on transferring standardized content, and enforcing patterns of top-down control cannot satisfy the demands of a digitalized, globalized, democratized, sustainability-focused and increasingly precarious world
[3]. But how must education change to align itself with the needs, rights and expectations of citizens?

Transformative digital learning (TDL) shifts the educational focus from predefined outcomes to emancipatory, digitally-mediated and augmented, inquiry and knowledge construction - "the expansion of consciousness through the transformation of worldviews and specific capacities of the self" [4]. Within this perspective, learners move through ongoing processes of cognitive and social change, establishing intermediate contextual learning goals and rethinking them once they are achieved. Are educators, who have trained for an industrial model of top-down instruction and predefined answers ready for this approach? How might teachers transform their roles, competencies and values to facilitate TDL? What transformation model can be used to guide the transition to TDL? These questions guided our previous research on student and teacher readiness for TDL within the post-Soviet space []], []], [7] , and many questions remain. In this article, we address the needs of two international partnership projects (Latvia-Canada and Ukraine-Latvia) dedicated to educational transformation in higher education.

\section{The CONTEXT: STARTING POSITIONS FOR}

EDUCATIONAL TRANSFORMATIONS IN LATVIA AND UKRAINE

As a global "megatrend," digitalization represents a broad program towards the intensive application of digital technologies to transform manufacturing, business models, urban infrastructures and institutions so as to pursue social innovation and address problems of sustainability [8-10]. However, as important as technological innovation may be, transforming human activity is much more than a technological issue. For example, without adequate digital competences, a deep appreciation of the affordances that digital technologies offer, and most importantly, a new vision of teaching and learning aligned with today's world, it is too easy to "pour 
old wine into new wine skins."

In post-Soviet nations, the Soviet system of higher education continues to exert cultural force over educational practices. This system was built on principles of practical training, alignment with collective goals, obedience to hierarchy and centrally administered planning and control [11]. The dissolution of Soviet system triggered significant dramatic changes to both Ukrainian and Latvian social institutions. In general terms, education was realigned to with western models, which emphasized legitimacy, transparency, local autonomy and pluralism. Despite economic limitations, each country made progress on several key elements of educational reform - developing new curricula and teaching materials, and establishing new links with international partners [12-14].

In Ukraine, after the student-initiated, "Euromaidan" revolution in 2014, declarations of educational reform emphasized more learning-centric, digitalized, democratized, and globalized education. However, Ukrainian educators are still struggling to achieve such reforms, often debilitated by lack of (personal, financial and technical) resources and a strategic roadmap well aligned with their context and culture [15]. At the microlevel, individual Ukrainian academics often innovate on their own, pursuing opportunities transformation through international partnerships, application of new learning models, greater academic autonomy and richer integration of digital technologies [7], [16]. It is perhaps noteworthy, however, that our measurement of digital competencies of students and professors at two Ukrainian universities [6],[]ㅡ indicate that many remain ill-prepared for fully online learning. In some cases, professors' skills even fell behind those of students: e.g., publishing media and ideas online, operating with audio/video files, program or automate procedures. These are creative, independentthinking skills, which are vital for 21st-century professionals.

In Latvia, the implementation of more democratic educational principles in universities was often more successful than in Ukraine [17], [18]. University autonomy was established, along with a new research infrastructures, a framework for quality assurance and a differentiated higher education system. Importantly, the Soviet restrictions in content and pedagogy were eliminated, which were especially significant in social sciences and humanities. However, some key issues are waiting to be addressed. For example, institutional transformation should include more democratic learning models that fully leverage the affordances of information and communication technologies (ICTs) and global networks. As McGuinness [19] argues, these changes require the professional development of faculty and researchers. To this end, several strategies, including strengthening doctoral programs, should be implemented. Given a shrinking student age cohort as well as migration and fluctuating economic conditions, it is likely that serious transformations of the institutional landscape in Latvia are just beginning [18].

As some researchers of post-Soviet educational transitions point out, a common characteristic of all countries of this group is a quantitative and qualitative shortage of research in HE institutions, with the focus of institutions remaining exclusively on teaching [18]. We see this as a potential hindering factor for post-industrial learning transformations.

In addition to the broad socio-contextual factors, readiness for innovative digitally-mediated learning also contains an important gender aspect. Although the number of females obtaining post-secondary education in both countries are higher than that of males, only onefifth of women work in high-tech industries in Ukraine, and about one quarter in Latvia [20]. This situation is typical around the world. Women largely tend to avoid ICT-related studies and are less likely to choose digital careers. In the EU, only $17,2 \%$ of IT-students and $16,7 \%$ of the employed IT-specialists in 2016 were females. The highest level of female participation in IT is in Bulgaria- $31 \%$ of women work in technology-related positions. At the same time, by 2020, the EU will lack 900,000 skilled ICT professionals [21], which makes the broad gender imbalance in IT a critical issue.

Importantly, our previous studies of general digital competencies in Ukraine and Georgia [6] , [5] did not reveal notable gender differences. Therefore, the gender divide in the IT community most probably relates to other socio-cultural factors [22]. Some researchers find that distinct gender attitudes toward technology is reproduced and institutionalized within educational systems themselves [23]. That is, females are largely enculturated to avoid working in a male-dominated IT sector. This disbalance in the labor market, which is bound to have negative consequences over the long term, might be partially addressed by incorporating more digitally focused learning models that emphasize human-computer interaction aligned with visions of a "smart-technology" society.

To summarize, the educational transformations in both Ukraine and Latvia should be democratically and digitally reformed with a focus on strengthening innovative research skills, self-directed (life-long) learning and emancipatory values such as those related to perspectival diversity, gender equality, interpersonal trust and freedom of expression.

\section{FROM TRADITIONAL TO TRANSFORMATIVE LEARNING: WHAT CHANGES ARE NEEDED?}

Mezirow, the founder of transformative learning theory, emphasized that adult learning must include reinterpreting the world rather than simply acting on prior beliefs, judgements, and feelings. He suggests, that learning goals should be considered in relation to both short- and longterm perspectives in a manner similar to the popular saying: giving a person a fish feeds her for a day (shortterm objectives), teaching her how to fish can feed her for a lifetime (long-term goals). An short-term objective may be to obtain job-related competencies, but the life-term goal could extend is to become a socially active critical thinker and an engaged global citizen [24]. 
Traditional (content-focused and highly structured and teaching models) [25] tend to emphasize the transfer of discipline-specific knowledge. However, for successful functioning in a transitioning and digitalized economy marked by disruptive innovations, this content-focused system of higher education has limited value. Universitylevel education would do well to focus on longer-term goals, and facilitating the development of digital skills, creative thinking, collaborative problem solving cognitive flexibility and emotional intelligence - the things that are difficult to automate with increasingly intelligent machines [26] Consistent with this perspective, Harkins [27] contrasts traditional learning to future-oriented digital education across five dimensions as shown in Table I.

Table I Differences in Traditional and Future-Oriented Models OF EDUCATION

\begin{tabular}{|c|c|c|}
\hline $\begin{array}{l}\text { Distinguishing } \\
\text { characteristics }\end{array}$ & $\begin{array}{l}\text { Traditional ("down- } \\
\text { load" and "open-ac- } \\
\text { cess") models } \\
\text { of digital education }\end{array}$ & $\begin{array}{l}\text { Future-oriented } \\
\text { ("knowledge and in- } \\
\text { novations producing") } \\
\text { models of education }\end{array}$ \\
\hline Meaning & $\begin{array}{l}\text { Dictated or socially } \\
\text { constructed with limit- } \\
\text { ed internet aid }\end{array}$ & $\begin{array}{l}\text { Socially constructed } \\
\text { and contextually } \\
\text { reinvented knowl- } \\
\text { edge, built through } \\
\text { selective individual } \\
\text { and team-driven em- } \\
\text { bodiments in practice }\end{array}$ \\
\hline $\begin{array}{l}\text { Knowledge } \\
\text { creating } \\
\text { process }\end{array}$ & $\begin{array}{l}\text { Transfer teach- } \\
\text { er-to-student, using } \\
\text { learning management } \\
\text { systems (LMS) or } \\
\text { MOOCs }\end{array}$ & $\begin{array}{l}\text { Technology-enabled } \\
\text { co-construction of } \\
\text { knowledge in learning } \\
\text { community, amplified } \\
\text { by critical creative } \\
\text { feedback loops } 24 / 7\end{array}$ \\
\hline $\begin{array}{l}\text { Schooling } \\
\text { location }\end{array}$ & $\begin{array}{l}\text { In buildings or online, } \\
\text { through hybrid or full } \\
\text { internet courses with } \\
\text { pre-recorded content }\end{array}$ & $\begin{array}{l}\text { Everywhere, emerging } \\
\text { in the globally net- } \\
\text { worked human body }\end{array}$ \\
\hline $\begin{array}{l}\text { Who teachers } \\
\text { are }\end{array}$ & Licensed professionals & $\begin{array}{l}\text { Everybody, who is an } \\
\text { innovation producing } \\
\text { source, backed up } \\
\text { by intuitive software } \\
\text { "partners" and human } \\
\text { collabourators }\end{array}$ \\
\hline $\begin{array}{l}\text { How em- } \\
\text { ployers view } \\
\text { graduates }\end{array}$ & $\begin{array}{l}\text { "Line workers", who } \\
\text { must be trained to } \\
\text { follow instructions }\end{array}$ & $\begin{array}{l}\text { Knowledge- and } \\
\text { innovation-produc- } \\
\text { ing co-workers and } \\
\text { entrepreneurs who can } \\
\text { initiate the new ways } \\
\text { and support sustain- } \\
\text { able development }\end{array}$ \\
\hline
\end{tabular}

Some leading collaborative learning models, adopting a problem-based learning (PBL) approach are well aligned with this vision of future-oriented learning. For example, the Fully Online Learning Community (FOLC) [28] (Fig.1), developed by EILAB researchers at the University of Ontario Institute of Technology (UOIT), Canada, which has several notable characteristics. It was initially conceived as an offshoot of the Community of Inquiry (CoI) model [29], one of the most thoroughly researched and widely used collaborative-constructivist theoretical models in the world [30],[31]. However, it removed "teaching presence" as a distinct dimension of learning so as to emphasize the need for (re)distributing educational control, reducing power distance between students and educators, and democratizing communication. Moreover, it inserted an emphasis on digital affordances and related digital competences - elements which the CoI considers extraneous. FOLC continues to evolve conceptually as it is applied daily at the Faculty of Education, UOIT as the basis for teacher education programs and deployed as a research framework for empirically studying the dynamics of fully-online community-based learning.

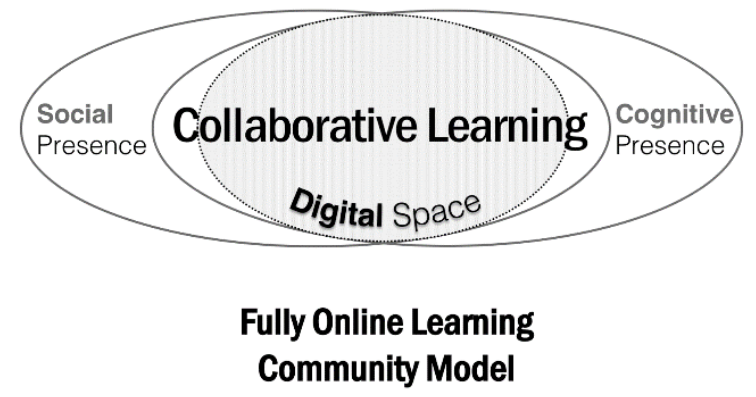

Fig. 1. Fully Online Learning Community (FOLC) model

FOLC-based research also recognizes the importance of socio-emotional interaction [32], and the innovative use of open digital affordances [33] (e.g., using mainstream social media for supporting collaborative inquiry and community-building). Most importantly, FOLC is designed as a flexible model, adaptable to the needs of learners in a variety of socio-cultural contexts. It is for this reason that we have used it as a guiding model in our own international teaching and learning projects.

\section{Modeling Learning Transformations with ACTIVITY THEORY}

Engeström, building directly on Vygotsky, Leontiev and other well-known cultural-historical psychologists from the early Soviet period [르],[35],[36] offers a visual theoretical model that includes an emphasis on individuals, tools, and several social and cultural mediators of collective technologically-mediated activity (Fig.2). This multi-triangle model, drawn with arrows to emphasize the dynamic nature of activity and the interrelatedness of the elements, offers a framework for envisioning educational transformation. More specifically, it provides an apparatus for modeling both current and desired educational practices (understood as activity systems), and exploring tensions between elements and other activity systems. Within activity theory, tensions are catalysts for pursuing critical analyses and concrete changes. The assumption is that professionals (e.g., teachers) are, or can become, active and empowered agents capable of making evidencebased decisions and changing their practices without an official mandate. In this sense, activity theory emphasizes and enables radical change "from below" through both individual and collective action. 


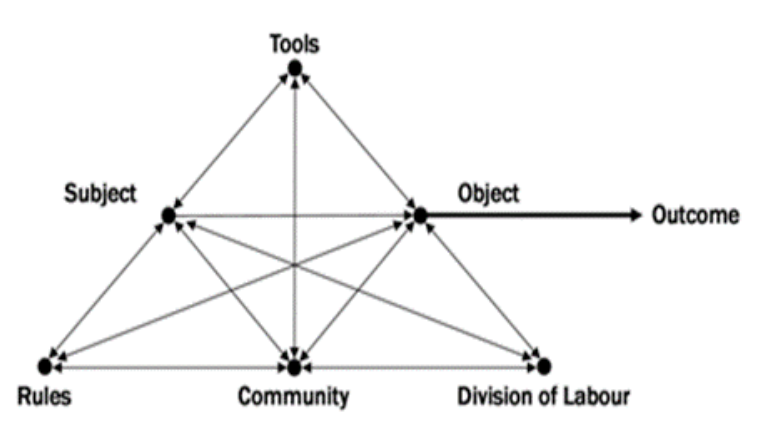

Fig. 2. Activity System model

The activity system model includes six constituent elements: the human agent, tools/artifacts, an object, a "community", rules, and division of labour. Each of these elements is modeled as a discrete entity which functions in a mediational relationship to the other elements. To more fully conceptualize these elements, they are presented in more detail.

- Subject: This is an active agent capable of taking purposeful action towards a goal by using the affordances of tools and technologies effectively, aligning her actions strategically with a driving collective objective (which is always flexible), and considering contextual opportunities and constraints.

- Object. The object or the "objective" represents the driving force of the activity. An object may be a need, desire, a vision of the future, a mission statement, a manifesto or a defined outcome. An activity without an object is meaningless!

- Tools. Tools include any instruments, artefacts or technologies used by participants to carry out an operation or action aligned with the activity. With today's digital society, a variety of digital hardware, software and systems are used to interact with each other and the world.

- Community. The community represents the relevant mediating collective, whether this is a team, workgroup, department, committee, class or something else. Collective activity always includes an individual and collective perspective, and there is no escape from the social nature of activity. Even actions taken alone are deeply connected to society and culture.

- Rules. These include both explicit and implicit ways for coordinating and mediating relations between the community members themselves and between them and the objects. Organization policies and values both function to mediate activities and participant perceptions.

- Division of Labour. From earliest recorded history, humans have coordinated their efforts to achieve desired outcomes more efficiently or effectively. Today, division of labour spans both human and machine agents in complex digitalized systems.
- Outcome. The outcome represents the end result of an activity. This outcome may become input for a new activity system. For example, a design or set of recommendations created from one group may be passed to another to implement.

Activity systems, by their nature, produce tensions, contradictions and innovations, which generate both resistance among participants and possibilities for transformations. With the assistance of human mediators, transformations can be guided through a cycle of "expansive learning" in which existing objectives and standard practices modelled, analyzed and reinvented. This cycle typically starts by identifying contradictions, and using the activity-system apparatus to map both the current and desired state of affairs. The next step is to gather motivation, resources and strategies for implementing the new model in practice. Achieving change requires communication, activism and ongoing learning. Indeed the most successful results will be achieved when change agents commit to democratic deliberation, critical reflection and divergent thinking [36].

To provide an example of how the activity system apparatus can be applied in practice, we have modelled both a (hypothetical) existing and target educational activity system based on our experience as educationaltransformation consultants (Fig.3).

\section{A Research Proposal}

The activity-system apparatus and transformation process described, is ideally suited for exploring potential educational transformations in post-Soviet contexts. Moreover, this model can be supplemented with several additional conceptual tools to help develop a general readiness for change among all participants. In our previous research, we have identified digital competences and personal-cultural orientations as especially important readiness factors at the micro-level. To measure these dimensions of readiness at the individual and group-levels we rely on several valid instruments. These include:

- Digital Competency Profiler (DCP) [37]

- Personal Cultural Orientation (PCO) [38]

- Cultural Values Scale (CVScale) [료

- Attitudes toward IT (AttIT) [39].

Data collected from these instruments can be analyzed using a number of statistical strategies that are designed based on the specific context of research and the guiding research questions. In any given study the focus may be on comparing different demographic segments, positioning participants in relation to established thresholds (that have been validated in relation to observed performance) or exploring individual changes over time. All of these situations require different analytical strategies. 


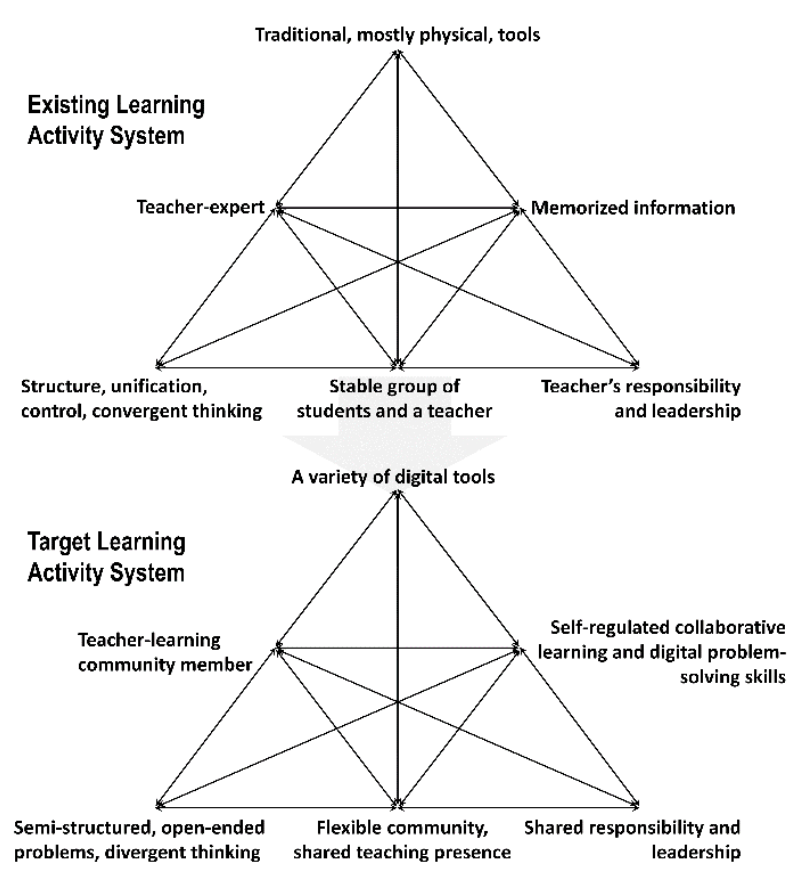

Fig. 3. The developmental model of the transition toward transformative learning

\section{DisCUSSION}

The outcomes of a transformation process and accompanying readiness research can be used as a firm foundation for creating new online courses, improving the existing academic program in pedagogy and creating transformative teachers' professional-development programs. Because transforming education in the direction of collaborative digitally-mediated learning is an ongoing process all participants must remain open to new ideas.

When studying values, there is always the question as to what extent they can be changed as a result of transformative learning, and what time interval is needed for changes to become noticeable. Hofstede emphasizes that fundamental values are deeply entrenched within social practices and institutions, and they do not change quickly [40]. However, there are reasons to believe that practices can change. Some scholars have observed that when online communities come together to learn or organize social change, new sub-cultural dispositions emerge that, have a direct effect on forms of communication, democratic functioning, uses of digital technologies, and collective social commitments. Even if emergent community values cause (initial) internal tensions in some participants and trigger forms of subconscious resistance (or culture shock), caring and tolerant communities can move forward together by being open and honest about their feelings, respecting diversity as a core value and practicing understanding. In short, there is expressed commitment, there will be opportunities to hack our "software of the mind" [41].

\section{Conclusions}

This theoretical proposal presented activity theory as a framework for modeling, analyzing and redesigning teaching and learning in higher education. Using the elements of Engeström's activity system, we suggested specific transformations toward digitalized and democratized learning that appear well-aligned with the needs of Latvia and Ukraine. Based on our research and experience we also noted that digital readiness and limiting gender perceptions are challenges to overcome. Our hope is that this proposal will provide learners and educators in higher-educational institutions in these countries with a practical apparatus for reforming university programs toward the requirements of a 21 st century economy and society.

\section{ACKNOWLEDGMENTS}

This article is supported by two funded projects: "Implementation of Transformative Digital Learning in Doctoral Program of Pedagogical Science in Latvia (DocTDLL) 1zp-2018/2-0180" and "Gender aspects of digital readiness and development of human capital in regions" (Ukraine-Latvia) (Nr.LV-UA/2018/3).

\section{REFERENCES}

[1] M. A. L. Luo, J; Boccardo, J, "New vision for education: Fostering social and emotional learning through technology," in "Industry Agenda," World Economic Forum, 2016, [Online]. Available: http://www3.weforum.org/docs/WEF New Vision for Education.pdf.

[2] T. Blayone, "Theorizing effective use of digital technology with activity theory," Accepted for publication in Technology, Pedagogy and Education, 2019.

[3] A. Till, V. Ratcheva, and S. Zakhidi, "The Future of Jobs Report " World Economic Forum, Centre for the New Economy and Society, 09/17/2018 2018, [Online]. Available: https://www. weforum.org/reports/the-future-of-jobs-report-2018.

[4] M. J. Elias et al., Promoting social and emotional learning: Guidelines for educators. Alexandria, Virgina, USA: Association for Supervision and Curriculum Development, 1997.

[5] T. Blayone, O. Mykhailenko, R. VanOostveen, O. Grebeshkov, O. Hrebeshkova, and O. Vostryakov, "Surveying digital competencies of university students and professors in Ukraine for fully online collaborative learning," Technology, Pedagogy and Education, vol. 27, no. 3, pp. 1-18, 2017.

[6] T. Blayone, O. Mykhailenko, M. Kokhan, M. Kavtaradze, R. vanOostveen, and W. Barber, "Profiling the digital readiness of higher education students for transformative online learning in the post-soviet nations of Georgia and Ukraine," International Journal of Educational Technology in Higher Education, vol. 15, no. 37, pp. 1-22, 2018.

[7] O. Mykhailenko, T. Blayone, and R. vanOostveen, "Exploring democratized learning and dimensions of culture for educational transformation in Ukraine," in RIDRU Conference: Higher Education Reforms in Post-Maidan Ukraine, October 25, 2016, ed. Alberta, Canada, 2016.

[8] R. Morrar, H. Arman, and S. Mousa, "The fourth industrial revolution (Industry 4.0): A social innovation perspective," Technology Innovation Management Review, vol. 7, no. 11, pp. 12-20, 2017.

[9] B. Wang, "The Future of Manufacturing: A New Perspective," Engineering, vol. 4, no. 5, pp. 722-728, 2018. 
[10] L. D. Xu, E. L. Xu, and L. Li, "Industry 4.0: State of the art and future trends," International Journal of Production Research, vol. 56, no. 8, pp. 2941-2962, 2018.

[11] A. Kuraev, "Soviet higher education: An alternative construct to the western university paradigm," Higher Education, vol. 71, pp. 181-193, 2016.

[12] B. Kutsyuruba, "Education in the period of post-Soviet transition in Ukraine," Demokratizatsiya, vol. 19, no. 3, pp. 287-309, 2011.

[13] D. V. Powell, S. Kuzmina, Y. Kuzmin, T. Yamchynska, and O. Shestopalyuk, "Using web-blended learning in Ukraine to facilitate engagement and globalize horizons: A pilot study," The Online Journal of Distance Education and e-Learning, vol. 2, no. 2, pp. 34-41, 2014.

[14] D. V. Powell, S. Kuzmina, T. Yamchynska, O. V. Shestopalyuk, and Y. Kuzmin, "Educational technologies for maturing democratic approaches to educational practices in Ukraine," Procedia-Social and Behavioral Sciences, vol. 176, pp. 378-385, 2015.

[15] S. Kvit, "The paradoxes of post-Soviet education," in KyivPost, ed. Kyiv, 2016.

[16] M. Hladchenko, D. Antonowicz, and H. de Boer, "Understanding the changes of the higher education governance in Poland and Ukraine: Institutional analysis," in The University as a Critical Institution?, D. R. and H. Eggins, Eds. Rotterdam, The Netherlands: Sense Publishers, 2017, pp. 55-74.

[17] T. Khavenson and M. Carnoy, "The unintended and intended academic consequences of educational reforms: The cases of Post-Soviet Estonia, Latvia and Russia," Oxford Review of Education, vol. 42, no. 2, pp. 178-199, 2016.

[18] A. Smolentseva, J. Huisman, and I. Froumin, Transformation of Higher Education Institutional Landscape in Post-Soviet Countries: From Soviet Model to Where? (25 Years of Transformations of Higher Education Systems in Post-Soviet Countries: Reform and Continuity). Palgrave Macmillan: Cham, Switzerland, 2018, pp. 1-43.

[19] A. C. J. McGuinness, "Reforms in the Baltics," International Higher Education, no. 25, pp. 13-14, 2001.

[20] A. Till, V. Ratcheva, and S. Zakhidi, "The Global Gender Gap Report " in "Insight Report," World Economic Forum, 2017, [Online]. Available: http://www3.weforum.org/docs/WEF GGGR_2017.pdf.

[21] European Parliament. (2018, 08-03-2018). More women in ICT: empowering women in the digital world [Online]. Available: http://www.europarl.europa.eu/news/en/headlines/society/20180301STO98927/more-women-in-ict-empoweringwomen-in-the-digital-world.

[22] J. C. Blickenstaff, "Women and science careers: leaky pipeline or gender filter?," Gender and education, vol. 17, no. 4, pp. 369386, 2005.

[23] P. C. Gorski, "What we're teaching teachers: An analysis of multicultural teacher education coursework syllabi," Teaching and Teacher Education, vol. 25, no. 2, pp. 309-318, 2009.

[24] J. Mezirow, "Transformative learning: Theory to practice," in New directions for adult and continuing education, vol. 1997no. 74). San Francisco, USA: Jossey-Bass Publishers, 1997, pp. 5-12.

[25] B. Levin, "Putting students at the centre in education reform," Journal of Educational Change, vol. 1, no. 2, pp. 155-172, 2000.
[26] C. B. Frey and M. A. Osborne, "The future of employment: How susceptible are jobs to computerisation?," Technological Forecasting and Social Change, vol. 114, pp. 254-280, 2017.

[27] A. M. Harkins, "Leapfrog principles and practices: Core components of education 3.0 and 4.0," Futures Research Quarterly, vol. 24, no. 1, pp. 19-31, 2008.

[28] T. Blayone, R. vanOostveen, W. Barber, M. DiGiuseppe, and E. Childs, "Democratizing digital learning: Theorizing the Fully Online Learning Community model," International Journal of Educational Technology in Higher Education, vol. 14, no. 13, pp. $1-16,2017$.

[29] D. R. Garrison, "Online Community of Inquiry review: Social, cognitive, and teaching Presence issues," Journal of Asynchronous Learning Networks, vol. 11, no. 1, pp. 61-72, 2007.

[30] P. P. E. Elicor, "The notion of pedagogical authority in the community of inquiry," Kritike, vol. 11, no. 2, pp. 80-92, 2017.

[31] W. Boston, S. R. Díaz, A. M. Gibson, P. Ice, J. Richardson, and K. Swan, "An exploration of the relationship between indicators of the community of inquiry framework and retention in online programs," Journal of Asynchronous Learning Networks, vol. 13, no. 3, pp. 67-83, 2014.

[32] R. vanOostveen, E. Childs, J. Clarkson, and K. Flynn, "Becoming close with others online: Distributed community building in online PBL courses," presented at the EdMedia 2015 World Conference on Educational Media and Technology, Montreal, Canada, June 22-25 2015, 2015.

[33] R. vanOostveen, M. DiGiuseppe, W. Barber, T. Blayone, and E. Childs, "New conceptions for digital technology sandboxes: Developing a Fully Online Learning Communities (FOLC) model," in EdMedia 2016: World Conference on Educational Media and Technology, G. Veletsianos, Ed. Vancouver, B.C., Canada: Association for the Advancement of Computing in Education (AACE), 2016, pp. 665-673.

[34] L. Vygotsky, Mind in society: Development of higher psychological processes. Cambridge, MA: Harvard University Press, 1978.

[35] A. N. Leontiev, Activity, consciousness and personality. Englewood Cliffs, NJ: Prentice-Hall, 1978. 1975.

[36] Y. Engeström, "Activity theory as a framework for analyzing and redesigning work," Ergonomics, vol. 43, no. 7, pp. 960-974, 2000.

[37] EILAB. (2017, October 29). Digital Competency Profiler [Online]. Available: https://dcp.eilab.ca/.

[38] P. Sharma, "Measuring personal cultural orientations: Scale development and validation," Journal of the Academy of Marketing Science, vol. 38, no. 6, pp. 787-806, 2009.

[39] A. A. Gokhale, P. E. Brauchle, and K. F. Machina, "Scale to measure attitudes toward information technology," International Journal of Information and Communication Technology Education, vol. 9, no. 3, pp. 13-26, 2013.

[40] G. Hofstede, Culture's consequences: Comparing values, behaviors, institutions and organizations across nations, Second ed. Thousand Oaks, California, USA: Sage Publications, 2001.

[41] G. Hofstede, "Culture and organizations," International Studies of Management \& Organization, vol. 10, no. 4, pp. 15-41, 1980. 